\title{
Analisa Insulasi Kebisingan Interior pada LRT Palembang Berdasarkan Nilai Sound Transmission Class
}

\author{
Mayang Ananda Putri dan Wiratno Argo Asmoro \\ Departemen Teknik Fisika, Fakultas Teknologi Industri, Institut Teknologi Sepuluh Nopember (ITS) \\ e-mail:wiratno@ep.its.ac.id
}

\begin{abstract}
Abstrak-Kereta api merupakan salah satu moda transportasi massal yang murah, efisien serta terjangkau untuk mengatasi kemacetan yang ada di Indonesia. Akan tetapi, kereta api juga memiliki masalah kebisingan yang dapat mengganggu kenyamanan penumpang di dalamnya. Bising kereta api disebabkan oleh berbagai sumber. Penelitian ini membahas mengenai analisa insulasi kebisingan interior pada LRT Palembang berdasarkan nilai sound transmission class yang tujuannya adalah mengurangi tingkat kebisingan yang dihasilkan sehingga tidak berdampak negatif bagi kesehatan penumpang di dalam kereta tersebut. Salah satu parameter untuk menilai kualitas serap bunyi suatu material adalah nilai STC. Berdasarkan hasil pengukuran, simulasi dan perhitungan menurut kondisi existing, didapatkan bahwa nilai STC pada bagian penyusun LRT Palembang yaitu pintu dan jendela masih belum memenuhi standar yaitu di bawah 30. Kemudian dilakukan rekomendasi bahan berdasarkan analisa STC dengan perhitungan dan simulasi. STC rekomendasi berdasarkan simulasi yaitu pada bagian pintu sebesar 31 (untuk material AA6063 T5) dan 30 (untuk material Tempered Glass), pada bagian jendela sebesar 31, dan side wall sebesar 43, sedangkan menurut perhitungan didapatkan nilai STC pada bagian pintu sebesar 29 (untuk material AA6063 T5) dan 27 (untuk material Tempered Glass), pada bagian jendela sebesar 33, dan side wall sebesar 47. Hasil analisa menunjukkan bahwa pada frekuensi $250 \mathrm{~Hz}$ masih belum memenuhi kondisi standar pengurangan bising yang dibutuhkan, sedangkan pada frekuensi 500 - $4000 \mathrm{~Hz}$, sebagian besar sudah memenuhi kondisi standar menurut permenhub. Rekomendasi material antara simulasi dan perhitungan menunjukkan perbedaan yang tidak jauh.
\end{abstract}

Kata Kunci-Bising kereta api, Sound Transmission Class.

\section{PENDAHULUAN}

$\mathrm{K}$ ERETA api merupakan salah satu moda transportasi massal yang murah, efisien serta terjangkau untuk mengatasi kemacetan yang ada di Indonesia. Akan tetapi, kereta api juga memiliki masalah kebisingan yang dapat mengganggu kenyamanan penumpang di dalamnya. Kebisingan tentu disebabkan oleh berbagai hal. Secara umum, masalah kebisingan dan getaran melibatkan tiga elemen utama: sumber, jalur transfer, dan penerima. Sumber utama kebisingan kereta api berkecepatan tinggi adalah kebisingan roda bergulir, pantograph suara, getaran aerodinamis, serta kebisingan peralatan dan getaran [1].

Salah satu parameter untuk menilai kualitas serap bunyi suatu material adalah nilai STC. STC atau yang merupakan kependekan dari sound transmission class merupakan kemampuan rata-rata transmission loss suatu bahan dalam mereduksi suara dari berbagai frekuensi. Dengan semakin tingginya STC, maka semakin bagus bahan tersebut dalam mereduksi suara. Dalam mereduksi suatu bunyi, STC bisa digolongkan berdasarkan berbagai nilai desibel. Kebanyakan, STC suatu bahan yang beredar dimasyarakat umum merupakan STC berjenis absorbsi atau serapan yang bekerja dengan melakukan penyerapan energi suatu bunyi sehingga output bunyi yang dihasilkan merupakan bunyi yang memiliki nilai desibel lebih kecil daripada bunyi input.

Melihat berbagai permasalahan di atas, kenyamanan penumpang yang berada di dalam kereta tentu perlu untuk diperhatikan. Kemudian dilakukan analisa insulasi kebisingan interior pada LRT Palembang berdasarkan nilai sound transmission class yang bertujuan untuk mengetahui nilai STC dari material penyusun LRT Palembang serta melakukan rekomendasi agar memenuhi kriteria bising yang ditetapkan sesuai standar sehingga tidak berdampak negatif bagi kesehatan penumpang di dalam kereta tersebut.

\section{II.TINJAUAN PUSTAKA}

\section{A. Sumber Kebisingan Kereta Api}

Bising yang dirasakan di dalam kereta dapat disebabkan oleh beberapa hal. Gambar 1 menggambarkan sumber-sumber bising pada rangkaian kereta lengkap.

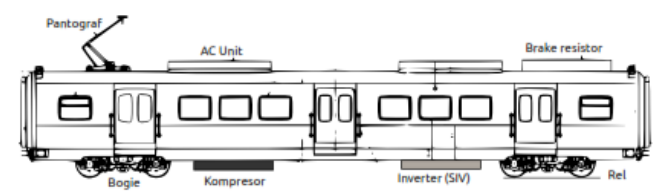

Gambar 1. Sumber-Sumber Bising pada Rangkaian Kereta Lengkap [2].

\section{B. Kriteria Bising}

Insulasi akustik merupakan faktor penting pada kenyamanan suatu ruangan. Menurut Peraturan Menteri Perhubungan Republik Indonesia 175 Tahun 2015 pasal 15 ayat 2a menjelaskan bahwa kebisingan yang terjadi pada kereta kecepatan normal dengan penggerak sendiri dalam kondisi ruang tertutup adalah maksimum $80 \mathrm{dBA}$ pada kecepaan maksimum operasi. LRT (Light Rail Transit) termasuk dalam kategori kereta kecepatan normal dengan penggerak sendiri dengan beban gandar maksimum 12 ton. Berdasarkan kriteria tersebut, maka standar kriteria bising kereta berpenggerak 
sendiri ditetapkan dengan NC curve sebesar 60 sehingga orang yang berada di dalamnya dapat menjalankan fungsi percakapan dengan mudah.

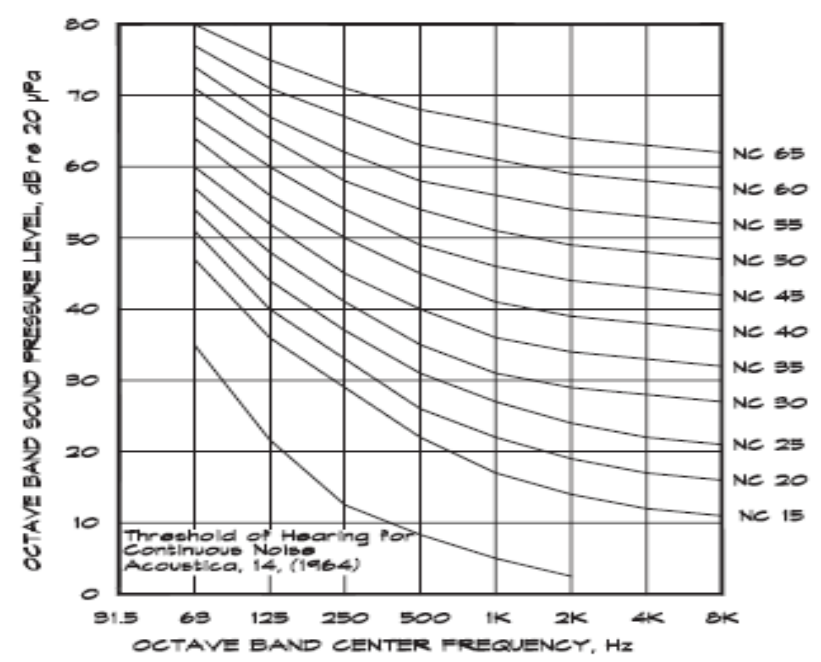

Gambar 2. Kurva Noise Criteria [3].

\section{Transmission Loss (TL)}

Ketika bunyi merambat melalui medium udara, perambatannya dapat dibatasi dengan pemasangan objek yang mampu menghalangi perambatan bunyi tersebut [4]. Transmission Loss atau rugi transmisi bunyi merupakan besaran nilai insulasi pada suatu partisi, dimana semakin besar nilai kerugiannya maka semakin besar kemampuan suatu bahan dalam menginsulasi suara [5]. Persamaan untuk dinding partisi yang terdiri dari dua material homogen (double panels) yang dipisahkan oleh rongga udara (cavity) yaitu sebagai berikut [6]:

$$
\begin{aligned}
R=\left\{\begin{array}{cl}
R_{M 1+M 2} & f<f o \\
R 1+R 2+20 \log (f . d)-29 & f o<f<f d \\
R 1+R 2+6 & f>f d
\end{array}\right. \\
\mathrm{f}_{0}=60 \sqrt{\frac{m 1+m 2}{m 1 \cdot m 2 \cdot d}} \\
\mathrm{f}_{\mathrm{d}}=\frac{55}{d}
\end{aligned}
$$

Dimana:

$$
\begin{array}{ll}
\mathrm{f} & =\text { Frekuensi }(\mathrm{Hz}) \\
\mathrm{d} & =\text { Jarak antar panel }(\mathrm{m}) \\
\mathrm{m}_{1} \text { dan } \mathrm{m}_{2} & =\text { Massa per luasan dari panel }\left(\mathrm{kg} / \mathrm{m}^{2}\right) \\
\mathrm{f}_{0} & =\text { Frekuensi resonansi dari rongga udara }(\mathrm{Hz}) \\
\mathrm{f}_{\mathrm{d}} & =\text { Frekuensi resonansi struktural }(\mathrm{Hz}) \\
\mathrm{R}_{1} \text { dan } \mathrm{R}_{2} & =\text { Transmission loss masing-masing material }
\end{array}
$$$$
\mathrm{M}_{1} \text { dan } \mathrm{M}_{2}=\text { Menandakan transmission loss harus dihitung }
$$
dari total massa kedua panel.

Dari persamaan diatas, $\mathrm{R}_{\mathrm{M} 1+\mathrm{M} 2}, \mathrm{R}_{1}$ dan $\mathrm{R}_{2}$ dapat dihitung dengan persamaan sebagai berikut [6]: $f<f c: R=20 \log (m f)$

$$
\begin{aligned}
& -10 \log \left[\ln \left(\frac{2 \pi f}{c o}\right) \sqrt{A}\right] \\
& +20 \log \left[1-\left(\frac{f}{f c}\right)^{2}\right]-42
\end{aligned}
$$

$$
\begin{aligned}
& f>f c: R=20 \log (m f) \\
& -10 \log \left[2 \eta t o t \frac{f}{f c}\right] \\
& -47 \\
& f c=\frac{\sqrt{3 c o^{2}}}{\pi h} \sqrt{\frac{\rho}{Y}} \\
& \text { Dimana: } \\
& \mathrm{c}_{\mathrm{o}} \quad=\text { Cepat rambat suara di udara }(340 \mathrm{~m} / \mathrm{s}) \\
& \mathrm{f}_{\mathrm{c}}=\text { Frekuensi kritis }(\mathrm{Hz}) \\
& \text { A }=\text { Luasan dinding }\left(\mathrm{m}^{2}\right) \\
& \eta_{\text {tot }}=\text { Total loss factor }\left(\mathrm{N} / \mathrm{m}^{2}\right) \\
& \rho=\text { Massa jenis panel }\left(\mathrm{kg} / \mathrm{m}^{3}\right) \\
& \mathrm{Y}=\text { Modulus Young dari panel }\left(\mathrm{N} / \mathrm{m}^{2}\right) \\
& \mathrm{h} \quad=\text { Ketebalan panel }(\mathrm{m})
\end{aligned}
$$

\section{Sound Transmission Class (STC)}

Kemampuan insulasi suatu material dapat diukur dalam suatu nilai Sound Transmission Class (STC). STC suatu material adalah kemampuan material dalam mereduksi bunyi (sound proof) ketika digunakan sebagai konstruksi. Nilai STC diukur tanpa satuan dari 0-100. Semakin tinggi nilai STC, semakin baik kemampuannya untuk mereduksi bunyi.

Tabel 1.

Klasifikasi Nilai STC [7]

\begin{tabular}{cl}
\hline \hline STC & \multicolumn{1}{c}{ Keterangan } \\
\hline $20-25$ & Sangat jelek, suara pelan dapat terdengar \\
$25-30$ & Buruk, suara normal jelas dan mudah didengarkan \\
$30-35$ & Cukup, suara keras cukup terdengar \\
$35-40$ & $\begin{array}{l}\text { Bagus, suara keras terdengar namun harus lebih } \\
\text { didengarkan lagi }\end{array}$ \\
$40-50$ & Sangat bagus, suara keras terdengar lemah \\
$50-60$ & $\begin{array}{l}\text { Sangat bagus sekali, suara keras terdengar sangat lemah } \\
\text { hampir tidak ada sama sekali }\end{array}$ \\
\hline \hline
\end{tabular}

STC memberikan perkiraan kinerja akustik dari dinding pada aplikasi isolasi suara udara [8]. Standar akustik sering diperbarui untuk menyertakan metode pengukuran terbaru dan paling akurat. Standar saat ini harus selalu dikonsultasikan dan ruang harus dirancang untuk memenuhinya [9].

\section{METODOLOGI PENELITIAN}

Pada bahasan ini akan dijelaskan mengenai langkah-langkah dalam melakukan peningkatan insulasi akustik dari material penyusun LRT Palembang pada bagian pintu dan jendela berdasarkan analisa Sound Transmission Class. Diagram alir penelitian dapat dilihat pada Gambar 2.

\section{ANALISA DATA DAN PEMBAHASAN}

\section{A. Data Pengukuran Lapangan Kondisi Bising LRT Palembang}

Hasil pengukuran tingkat kebisingan kereta api didapatkan spektrum frekuensi sumber bising LRT Palembang yang diukur pada kondisi statis dan dinamis memiliki spektrum yang hampir sama yaitu dominan pada frekuensi tengah 1/3 oktaf yaitu 500 $-4000 \mathrm{~Hz}$. Hasil pengukuran spektrum kebisingan pada kondisi statis dan dinamis dapat dilihat sebagaimana pada Gambar 3 dan Gambar 4. 




Gambar 2. Diagram Alir Studi.



Gambar 3. Karakter Bising LRT kondisi dinamis.

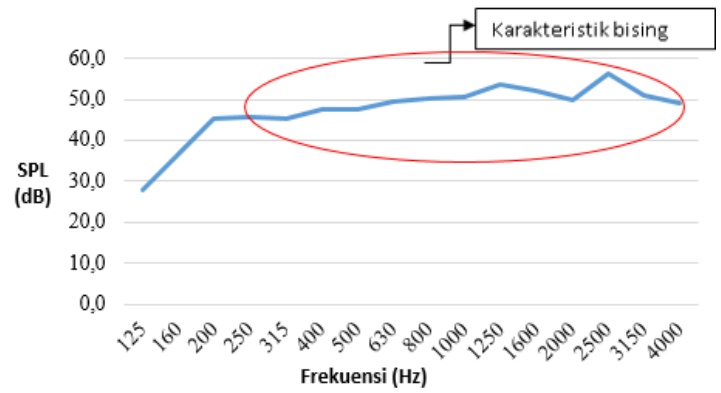

Gambar 4. Karakter Bising LRT Kondisi Statis.

Berdasarkan pengukuran karakteristik bising LRT pada kondisi statis dan dinamis, didapatkan bahwa bising LRT dominan pada frekuensi tinggi. Bising pada frekuensi tinggi dapat dikategorikan sebagai airborne noise yaitu perambatan bunyi melalui medium udara. Karakter bising pada frekuensi tinggi dapat dijadikan acuan untuk insulasi bising menggunakan analisa STC.

Pengambilan data STC dilakukan di final test PT INKA (Persero) Madiun pada siang hari ketika peralatan yang dapat beroperasi dalam keadaan statisioner dioperasikan, termasuk peralatan tambahan juga dioperasikan. Pengambilan data dilakukan pada area pintu dan jendela, untuk setiap objek pengukuran dilakukan pengambilan data sebanyak 3 kali, untuk satu kali pengambilan data dilakukan selama 5 detik dengan membunyikan sumber bunyi TOA Box Speaker ZS-1030 B/W (30 Watt) yang berada di luar gerbong LRT Palembang. Berdasarkan pengukuran yang telah dilakukan, maka didapatkan hasil SPL ruang sumber dan penerima untuk perhitungan transmission loss yang akan digunakan sebagai dasar perhitungan STC dengan hasil nilai STC tertinggi terdapat pada jendela saat pengukuran titik kedua dalam kondisi kompresor menyala yaitu sebesar 26 dan nilai terendah pada pintu titik pertama yaitu sebesar 10 .

Tabel 2.

Nilai STC LRT Palembang Berdasarkan Pengukuran Langsung

\begin{tabular}{cccc}
\hline \hline No & Bagian LRT Palembang & Posisi Pengukuran & STC \\
\hline \multirow{3}{*}{1} & \multirow{3}{*}{ Pintu } & Titik pertama & 10 \\
& & Titik kedua & 23 \\
& & Titik Ketiga & 22 \\
2 & \multirow{2}{*}{ Jendela } & Titik pertama & 19 \\
& & Titik kedua & 26 \\
& & Titik Ketiga & 25 \\
\hline \hline
\end{tabular}

Berdasarkan Tabel 2, dapat dilihat bahwa nilai STC pada pintu dan jendela masih belum memenuhi standar (masih di bawah 30). Nilai STC pada pintu posisi pengukuran titik kedua hampir mendekati nilai STC pada pintu titik ketiga, begitu juga nilai STC jendela pada titik kedua memiliki nilai yang hampir sama dengan jendela pada titik ketiga, hal itu terjadi karena titik kedua dan titik ketiga memiliki jarak serta posisi sudut yang sama terhadap sumber bunyi.

Nilai STC pada pintu dan jendela titik pertama memiliki nilai yang lebih kecil jika dibandingkan dengan titik kedua dan titik ketiga, seharusnya pada titik pertama memiliki nilai STC paling tinggi karena paling dekat dengan sumber bunyi. Secara teori 
dikatakan bahwa bunyi akan bergerak lurus dan akan semakin melemah seiring dengan menjauhnya dari arah sumber bunyi. Penyebab kecilnya tingkat tekanan bunyi pada titik pertama terjadi karena beberapa faktor seperti adanya material lain di sekitar area pengukuran sehingga sumber bunyi yang mengenai dinding partisi ada yang diserap dan dipantulkan oleh material lain sehingga berdampak pada pengurangan nilai transmission loss sehingga menyebabkan STC pada titik pertama bernilai kecil jika dibandingkan dengan titik kedua dan ketiga.

\section{B. Simulasi STC LRT Palembang dengan Software AFMG Soundflow}

Tabel 3.

Nilai STC pada LRT Palembang Berdasarkan Simulasi

\begin{tabular}{cclc}
\hline \hline No & $\begin{array}{c}\text { Bagian LRT } \\
\text { Palembang }\end{array}$ & \multicolumn{1}{c}{ Material Penyusun } & STC \\
\hline 1 & Sidewall & FRP 3 mm, Polyurethane 50 & 29 \\
& mm, AL 6061 T6 2,4 mm & 30 \\
2 & PL6065 T5 2,5 mm & 29 \\
& & $\begin{array}{l}\text { Tempered Glass 2,2 mm } \\
\text { Tempered Glass } 8 \mathrm{~mm}, \text { PVB } \\
1,14 \mathrm{~mm}, \text { Tempered Glass } 5\end{array}$ & 28 \\
& Jendela & mm & \\
\hline \hline
\end{tabular}

Setelah dilakukan simulasi sesuai kondisi existing, kemudian dilakukan validasi antara nilai STC hasil pengukuran langsung, perhitungan dan dan hasil simulasi sebagaimana pada tabel 4 .

Tabel 4.

Perbandingan Nilai STC

\begin{tabular}{|c|c|c|c|c|c|}
\hline \multirow[b]{2}{*}{$\begin{array}{l}\text { Bagian LRT } \\
\text { Palembang }\end{array}$} & \multicolumn{3}{|c|}{ STC Existing } & \multirow{2}{*}{$\begin{array}{c}\text { STC } \\
\text { Perhitungan }\end{array}$} & \multirow{2}{*}{$\begin{array}{c}\text { STC } \\
\text { Simulasi }\end{array}$} \\
\hline & $\begin{array}{c}\text { Titik } \\
1\end{array}$ & $\begin{array}{c}\text { Titik } \\
2\end{array}$ & $\begin{array}{c}\text { Titik } \\
3\end{array}$ & & \\
\hline Pintu & 10 & 23 & 22 & $\begin{array}{c}28 \text { (AA6063 } \\
\text { T5) ; } 26 \\
\text { (Tempered } \\
\text { Glass) }\end{array}$ & $\begin{array}{c}29 \\
\text { (AA6063 } \\
\text { T5) ; } 30 \\
\text { (Tempered } \\
\text { Glass) }\end{array}$ \\
\hline Jendela & 19 & 26 & 25 & 26 & 28 \\
\hline
\end{tabular}

Pada Tabel 4, terdapat perbedaan nilai STC antara hasil pengukuran langsung, perhitungan dan hasil simulasi. Hal itu terjadi karena pada perhitungan dan simulasi mempertimbangkan parameter material dari bahan saja, sedangkan pada pengukuran menurut standar, diperhatikan juga faktor lingkungan dari dinding partisi yang akan diuji dan juga terdapat material-material lain di sekitar yang akan berpengaruh terhadap hasil pengukuran lapangan.

Berdasarkan data yang diperoleh dari pengukuran di lapangan, perhitungan dan simulasi, dapat dilihat bahwa kinerja material penyusun LRT Palembang masih belum memenuhi standar. STC pada material penyusun pintu dan jendela belum mencapai angka diatas 30 sehingga masih belum memenuhi kriteria standar STC yang cukup baik sesuai standar ASTM E413-16. Sedangkan menurut Peraturan Menteri Perhubungan Republik Indonesia No 175 Tahun 2015, batas maksimum kebisingan pada kereta adalah 80 dBA pada kecepatan maksimum operasi. Sedangkan NC standar pada kereta api untuk kondisi percakapan sebesar 60 [7]. Untuk mendapatkan nilai acuan per frekuensi, maka diplot pada kurva Noise Criteria (NC) pada tiap spektrum frekuensi [4] sehingga dapat diketahui pengaruh eksperiman pada nilai reduksi kebisingan tiap frekuensi yang dapat dilihat pada Tabel 5 dan Gambar 12 sebagai perbandingan tingkat kebisingan kereta terhadap kondisi ideal.

Tabel 5. menunjukkan pengurangan SPL pada spektrum bising agar memenuhi kondisi standar. Pada frekuensi $63-250$ $\mathrm{Hz}$ pengurangan SPL yang dibutuhkan bertanda negatif, hal itu menunjukkan bahwa spektrum bising yang ada sudah berada di bawah standar kebisingan sehingga tidak perlu dilakukan pengurangan SPL pada frekuensi tersebut. Sedangkan pada frekuensi $500-4000 \mathrm{~Hz}$ menunjukkan kebisingan dominan sehingga pengurangan SPL bertanda positif dan diperlukan adanya pengurangan SPL. Penurunan SPL digunakan sebagai pertimbangan dalam melakukan insulasi. Oleh karena itu perlu dilakukan simulasi untuk rekomendasi perbaikan kualitas penyerapan bunyi dari material LRT untuk mereduksi kebisingan yang terjadi.

Tabel 5.

Pengurangan SPL yang Dibutuhkan

\begin{tabular}{|c|c|c|c|c|c|c|c|}
\hline $\begin{array}{c}\text { Frekuensi } \\
(\mathrm{Hz})\end{array}$ & 63 & 125 & 250 & 500 & 1000 & 2000 & 4000 \\
\hline $\begin{array}{l}\text { Spektrum } \\
\text { Bising (dB) }\end{array}$ & 63,4 & 64,8 & 70,5 & 90,9 & 96,3 & 89,4 & 79,8 \\
\hline $\begin{array}{l}\text { Permenhub } \\
175 \text { th } 2015 \\
(80 \mathrm{dBA})\end{array}$ & 88 & 80 & 74 & 71 & 71 & 71 & 71 \\
\hline $\begin{array}{l}\text { NC } 55 \\
\text { Pengurangan } \\
\text { SPL yang }\end{array}$ & 77 & 71 & 67 & 63 & 61 & 59 & 58 \\
\hline $\begin{array}{l}\text { dibutuhkan } \\
\text { berdasarkan } \\
\text { Permenhub } \\
\text { (dB) } \\
\text { Pengurangan } \\
\text { SPL yang }\end{array}$ & $-24,6$ & $-15,2$ & $-3,5$ & 19,9 & 25,3 & 18,4 & 8,8 \\
\hline $\begin{array}{l}\text { dibutuhkan } \\
\text { berdasarkan } \\
\text { Rating NC }\end{array}$ & $-13,6$ & $-6,2$ & 3,5 & 27,9 & 35,3 & 30,4 & 21,8 \\
\hline
\end{tabular}

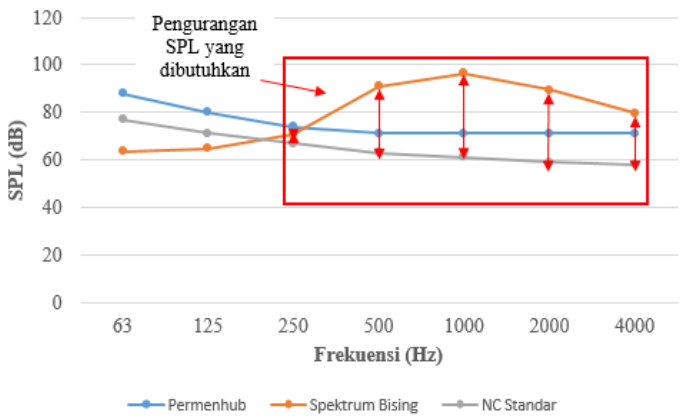

Gambar 5. Perbandingan Tingkat Kebisingan Kereta dengan Kondisi Ideal.

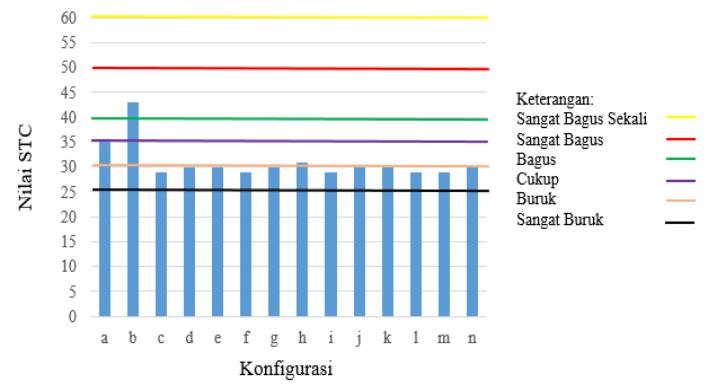

Gambar 6. Grafik STC Side Wall. 


\section{Simulasi Rekomendasi Material LRT Palembang}

Pada simulasi side wall, pintu dan jendela digunakan variasi berupa perubahan ketebalan material untuk setiap lapisan dan perubahan parameter akustik yaitu Density, Young's Modulus, Poisson's Ratio, Bending Loss Factor dengan hasil yang disajikan seperti pada Gambar 6.

Berdasarkan Gambar 6, rekomendasi terbaik yaitu nilai STC sebesar 43 dengan material FRP $=25 \mathrm{~mm}$, Polyurethane $=19$ $\mathrm{mm}$, AA6061 T6 $=11,4 \mathrm{~mm}$. Nilai STC 43 termasuk dalam kategori sangat bagus.

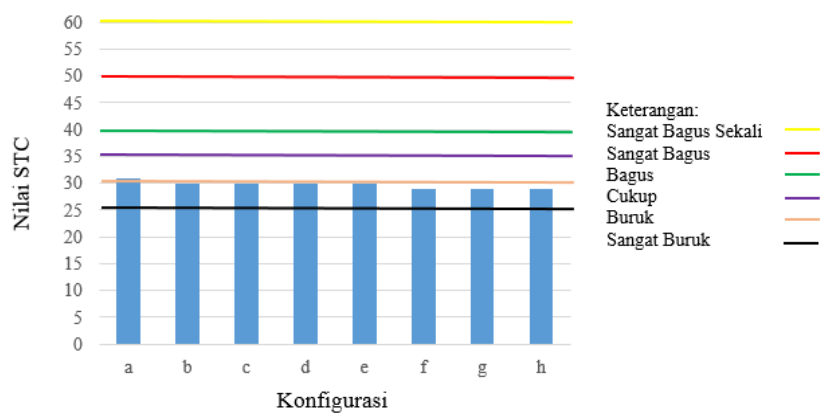

Gambar 7. Grafik STC Pintu.

Berdasarkan Gambar 7, rekomendasi terbaik yaitu nilai STC sebesar 31 untuk material AA6063 T5 dan 30 untuk material tempered glass. Nilai STC 31 dan 30 termasuk dalam kategori cukup.

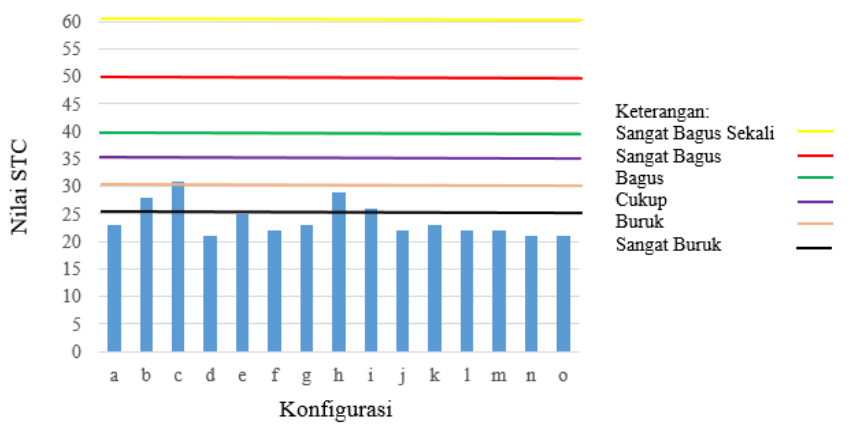

Gambar 8. Grafik STC Jendela.

Berdasarkan Gambar 8, rekomendasi terbaik yaitu nilai STC sebesar 31 dengan material Tempered Glass $1=5 \mathrm{~mm}$, gap $\mathrm{PVB}=4.54 \mathrm{~mm}$, Tempered Glass $2=5 \mathrm{~mm}$. Nilai STC 31 termasuk dalam kategori cukup. Rekomendasi tidak mungkin dimaksimalkan hingga kategori sangat bagus sekali karena terdapat syarat batas ketebalan pintu, jendela dan side wall serta harus memperhatikan kondisi dari material yang digunakan sehingga tidak mengubah karakteristik material ketika dilakukan variasi terhadap material properties. Peningkatan insulasi material dapat dilihat berdasarkan kenaikan nilai transmission loss antara kondisi sebenarnya dan setelah dilakukan rekomendasi. Besarnya peningkatan tersebut menunjukkan kinerja material dalam menginsulasi bunyi setelah dilakukan rekomendasi. Peningkatan transmission loss pada pintu, jendela dan side wall dapat dilihat pada Gambar 9 Gambar 11.

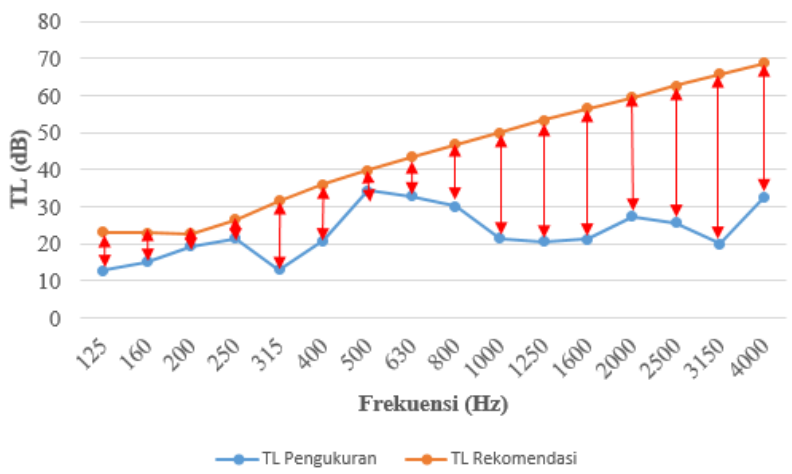

Gambar 9. Perbandingan Transmission Loss Side Wall Pengukuran dan Rekomendasi.

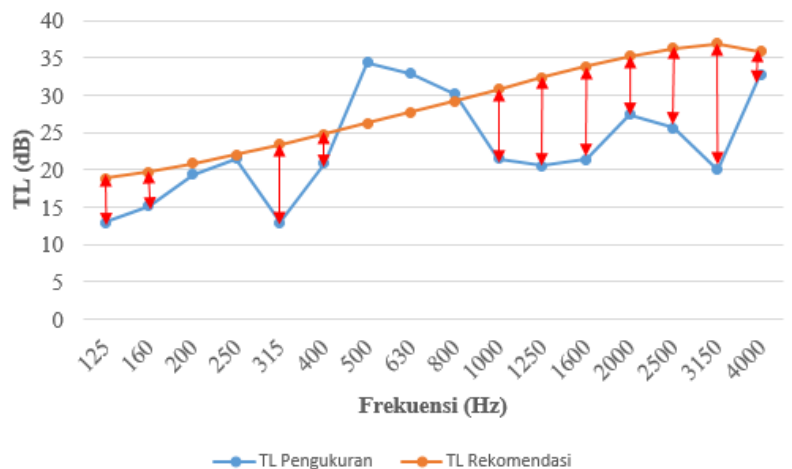

Gambar 10. Perbandingan Transmission Loss Pintu Pengukuran dan Rekomendasi.

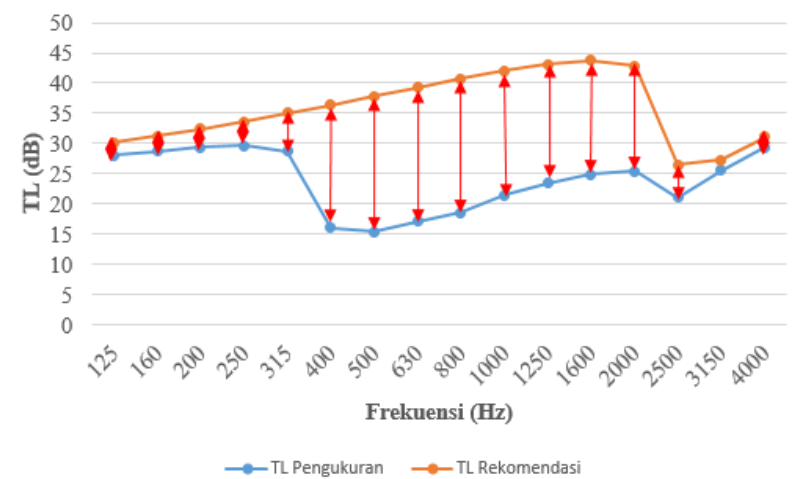

Gambar 11. Perbandingan Transmission Loss Jendela Pengukuran dan Rekomendasi.

Berdasarkan Gambar 9 - Gambar 11, garis berwarna biru menunjukkan transmission loss menurut pengukuran, sedangkan garis berwarna orange menunjukkan transmission loss yang direkomendasikan. Berdasarkan simulasi rekomendasi yang telah dilakukan, menunjukkan hasil bahwa pada frekuensi $250 \mathrm{~Hz}$ masih belum memenuhi kondisi standar pengurangan bising yang dibutuhkan menurut tabel 5., sedangkan pada frekuensi $500-4000 \mathrm{~Hz}$, sebagian besar sudah memenuhi kondisi standar menurut permenhub. Standar kebisingan menurut permenhub masih berada dibawah standar kebisingan berdasarkan kriteria bising menurut fungsi ruang, sehingga perlu dilakukan peningkatan agar kebisingan yang dihasilkan memiliki kriteria yang lebih tinggi. 


\section{V.KESIMPULAN/RINGKASAN}

1. Nilai sound transmission class pada bagian penyusun LRT Palembang sesuai kondisi existing pada pintu titik 1, titik 2, titik 3 dan jendela titik 1 , titik 2 , titik 3 secara berturut-turut adalah $10,23,22,19,26$ dan 25 , sedangkan menurut perhitungan, nilai STC pada pintu sebesar 28 (untuk material AA6063 T5) dan 26 (untuk material Tempered Glass) serta pada jendela sebesar 26. Selain STC kondisi existing dan perhitungan, juga didapatkan STC berdasarkan simulasi yaitu pada pintu sebesar 29 (untuk material AA6063 T5) dan 30 (untuk material Tempered Glass) serta pada jendela sebesar 28.

2. Hasil variasi material pada setiap bagian penyusun LRT Palembang menunjukkan bahwa mengubah ketebalan dari material memiliki pengaruh yang cukup besar terhadap perubahan nilai STC, sedangkan mengubah material properties dari suatu bahan tidak memiliki pengaruh yang cukup besar terhadap peningkatan nilai STC

3. Untuk mengurangi tingkat kebisingan interior pada LRT Palembang dilakukan rekomendasi bahan berdasarkan analisa STC dengan perhitungan dan simulasi. STC rekomendasi berdasarkan simulasi yaitu pada bagian pintu sebesar 31 (untuk material AA6063 T5) dan 30 (untuk material Tempered Glass), pada bagian jendela sebesar 31, dan side wall sebesar 43, sedangkan menurut perhitungan didapatkan nilai STC pada bagian pintu sebesar 29 (untuk material AA6063 T5) dan 27 (untuk material Tempered Glass), pada bagian jendela sebesar 33, dan side wall sebesar 47. Rekomendasi material antara simulasi dan perhitungan menunjukkan perbedaan yang tidak jauh.

\section{DAFTAR PUSTAKA}

[1] J. Zhang, X. Xiao, X. Sheng, C. Zhang, R. Wang, and X. Jin, "SEA and contribution analysis for interior noise of a high speed train," Appl. Acoust., vol. 112, pp. 158-170, Nov. 2016.

[2] PT INKA, "Report Noise KRL PT INKA," Madiun, 2016.

[3] M. Long, Architectural acoustics. Elsevier/Academic Press, 2006.

[4] Mediastika and E. Christina, Akustika Bangunan: Prinsip-prinsip dan Penerapannya di Indonesia. Jakarta: Erlangga, 2005.

[5] E. . Mediastika, Material Akustik Pengendali Kualitas Bunyi pada Bangunan. Yogyakarta, 2009.

[6] J. Ellefsen and S. Olafsen, "Empirical calculation of sound insulation in lightweight partition walls with separate steel studs," 2010.

[7] American Society for Testing and Materials (ASTM), ASTM E 413 Classification for Rating Sound Insulation. USA: ASTM International ASTM (American Society for Testing and Materials.

[8] ASTM International, "Sound Transmission Class Rating for Concrete Masonry Walls," 2012.

[9] R. S. Ulrich et al., "A review of the research literature on evidencebased healthcare design.," HERD, vol. 1, no. 3, pp. 61-125, 2008. 